Original paper

\title{
Treg cells in the course of chronic hepatitis $C$ virus infection partially normalize in longitudinal observation after successful DAA treatment regardless of hepatic fibrosis stage
}

\author{
Agata Zientarska', Mariusz Kaczmarek2,3, Iwona Mozer-Lisewska' ${ }^{1}$, Arleta Kowala-Piaskowska', Aleksandra Witkowska', \\ Jan Żeromski ${ }^{4}$ \\ 'Chair and Department of Infectious Diseases, Hepatology and Acquired Immunodeficiencies, Karol Marcinkowski University of Medical \\ Sciences, Poznan, Poland \\ ${ }^{2}$ Chair of Clinical Immunology and Department of Cancer Immunology, Karol Marcinkowski University of Medical Sciences, Poznan, Poland \\ ${ }^{3}$ Department of Diagnostics and Cancer Immunology, Greater Poland Cancer Centre, Poznan, Poland \\ ${ }^{4}$ Chair of Clinical Immunology, Karol Marcinkowski University of Medical Sciences, Poznan, Poland
}

\begin{abstract}
Aim of the study: Elevated circulating CD4+CD25+ Foxp $3+$ regulatory T cells in patients with chronic hepatitis $C$ (CHC) play an unspecified role in liver fibrosis development. This study aimed to determine whether Treg cells diminish after successful treatment with directacting antivirals (DAA) in patients at different liver fibrosis stages. Material and methods: We examined 44 patients with CHC (including 29 with liver cirrhosis) seven days before DAA treatment (T0), six months later (T1) and then 22 of them were examined one year (T2) after the first dose. Subsequently, these were compared with 28 volunteers without hepatitis C virus (HCV) (15 with excessive alcohol intake). We assessed the degree of liver fibrosis with FibroScan, aspartate transaminase (AST) to platelet ratio index (APRI), Fibrolndex, the Forns index and Fib-4. Circulating Treg cells were measured using flow cytometry.

Results: All patients achieved a sustained virological response (SVR). After the treatment, all liver fibrosis indicators decreased significantly. The number of circulating Tregs was lower in healthy controls than in patients with $\mathrm{CHC}\left(0.0066 \times 10^{3} \mathrm{cells} / \mu \mathrm{l}\right.$ and $0.0084 \times 10^{3} \mathrm{cells} / \mu \mathrm{l}$, respectively, $\left.p=0.048\right)$. After the treatment we observed an insignificant change to $0.0047 \times 10^{3}$ cells $/ \mu \mathrm{l}$ for T1 $(p>0.05)$ and a significant fall to $0.0041 \times 10^{3} \mathrm{cell} / \mathrm{s} / \mu \mathrm{l}$ for T2 $(p=0.03)$. There was no correlation between the degree of hepatic fibrosis and number of Tregs or post-treatment dynamics.

Conclusions: Our study shows that Treg cells normalize gradually over a prolonged period of time after a successful DAA treatment. Their number and dynamics remain independent of liver fibrosis degree. The correlation of this revelation with metabolic disorders, increased susceptibility to infections or persistent risk of HCC remains unclear.
\end{abstract}

Key words: hepatitis C, liver fibrosis, Treg cells.

Address for correspondence:

Agata Zientarska, Chair and Department of Infectious Diseases, Hepatology and Acquired Immunodeficiencies, Karol Marcinkowski University of Medical Sciences, Poznan, Poland, e-mail: agatakierepa@gmail.com

\section{Introduction}

CD4+ CD25+ Foxp3+ regulatory T cells (Tregs) are a specialized subpopulation of $\mathrm{T}$ cells that plays an essential role in the protection against the immune system's excessive activity, maintaining immune homeostasis. They suppress the activation, proliferation, differentiation, and effector functions of many 
immune cells, including T cells, B cells, NK cells, and dendritic cells [1].

Almost 20 years ago, higher levels of circulating CD4+ $\mathrm{CD} 25+\mathrm{T}$-cells were described in patients with chronic hepatitis $\mathrm{C}(\mathrm{CHC})$ for the first time [2]. Since then multiple studies [3] have confirmed this phenomenon, showing a positive correlation between Treg cells, the viral load [3] and their independence from hepatic function [4]. Treg cells' proliferation is probably stimulated directly by hepatitis $\mathrm{C}$ virus (HCV) core protein and transforming growth factor $\beta$ (TGF- $\beta$ ) secreted by infected hepatocytes [5].

In the acute phase of HCV infection, Tregs downregulate immune-mediated liver damage mechanisms [3]. In the chronic phase, the situation becomes more complex, and Tregs' role in the development of hepatic fibrosis appears controversial. High levels of intrahepatic Treg cells are correlated with less extensive fibrosis [6] but forecast a poor outcome in patients with hepatocellular carcinoma (HCC) [7]. Inconclusive results of the studies suggest that different subsets of Treg cells might have opposite effects on HCV-related liver injuries [3].

The number of Treg cells in blood drops for patients who have spontaneously eliminated the virus [8]. In those $\mathrm{CHC}$ patients who underwent interferon (IFN)-combination therapy, Treg-mediated immunosuppression was lower during and after the treatment, regardless of the treatment outcome. It was higher in patients with a sustained viral response [9]. Little is known about the behaviour of these cells after successful, IFN-free treatment of HCV. This study aimed to assess whether Treg cells diminish after successful treatment with directly acting antivirals (DAA) in patients at different liver fibrosis stages.

\section{Material and methods}

We collected a study group from among patients treated in 2018 and 2019 at the Department of Infectious Diseases, Hepatology and Acquired Immunodeficiencies of Poznan University of Medical Sciences. It consisted of 44 patients with $\mathrm{CHC}$ genotype $1 \mathrm{~b}$ at different stages of liver fibrosis qualified for DAA treatment. The following exclusion criteria were applied: presence of HCC, human immunodeficiency virus (HIV) coinfection, HBsAg presence, administration of any immunomodulatory or immunosuppressive drugs, elevated $\mathrm{C}$ reactive protein (CRP), leukocytosis or any active infection other than $\mathrm{CHC}$.

We tested the subjects up to seven days before the treatment (T0) and after the completed regimen - an average of 198 days after the first dose (T1). 176 days later, twenty-two of them were tested again (T2). Twenty-two patients were treated with sofosbuvir/ledipasvir (including 16 regimens with ribavirin), ombitasvir/ paritaprevir/ritonavir/dasabuvir was administered to seven, another seven had sofosbuvir/velpatasvir, grazoprevir/elbasvir was given to four and four were treated with glecaprevir/pibrentasvir. We applied the regimens according to Polish recommendations [10]. All the patients completed the therapy and achieved a sustained virological response (SVR). Then, we enrolled a control group that consisted of 28 volunteers without HCV infection. The control group was subject to the same exclusion criteria as the study group. Since diverse fibrosis levels were present within our study group, our goal was to collect a control group with a comparable spread but without an active liver-damaging factor that could influence the Treg cells. Fifteen of our volunteers had a history of excessive alcohol intake (with at least a six-month abstinence period before the study), including individuals with hepatic fibrosis due to alcohol-related liver disease.

The transient elastography technique using a FibroScan Compact device (Echosens, Paris, France) in compliance with the manufacturer's instructions was employed to measure liver stiffness [11].

To increase the accuracy of liver fibrosis assessment, we also used four non-invasive methods. First the widely used APRI [12], characterised by well-documented statistical properties, was calculated according to the following formula: ([AST/ULN]/number of platelets $\left.\left[\times 10^{9} / 1\right]\right) \times 100$, where AST - aspartate aminotransferase, ULN - upper limit of normal (in this case, $23 \mathrm{IU} / \mathrm{ml}$ ). Then we calculated the FIB-4 index, used primarily to assess the severity of liver disease in patients with HIV/HCV co-infection [13], calculated as age $\times \mathrm{AST} /\left(\left(\right.\right.$ platelet count $\left.\left.\left[\times 10^{9} / 1\right]\right) \times \mathrm{ALT} 1 / 2\right)$, where AST and ALT are aspartate and alanine aminotransferase, respectively. FibroIndex [14] was another fibrosis indicator, relying among others on the concentration of $\gamma$-globulin in the serum, calculated according to the following formula: $1.738-0.064 \times$ number of platelets $\left[\times 10^{4} / \mathrm{mm}^{3}\right]+0.005 \times$ AST $[\mathrm{IU} / \mathrm{l}]+0.463$ $\times \gamma$-globulins [g/dl]. Finally, the Forns score [15] was used, calculated as: $7.811-3.131 \times \ln$ (number of platelets $\left.\left[\times 10^{9} / 1\right]\right)+0.781 \times \ln ($ GGTP $)+3.467 \times \ln ($ age $)$ - $0.014 \times$ chol $[\mathrm{mg} / \mathrm{dl}]$, where GGTP is $\gamma$-glutamyltranspeptidase, and chol is total serum cholesterol.

Cell immunophenotyping was performed by flow cytometry using the direct fluorescence meth-

Table 1. Antibodies used in the study for cell immunophenotyping

\begin{tabular}{lccc}
\hline Antibody & Fluorochrome & Clone & Source \\
\hline Mouse anti-human CD4 & PE & SK3 & BD Biosciences \\
\hline Mouse anti-human CD25 & PE-Cy ${ }^{\mathrm{TM} 7}$ & 2A3 & BD Biosciences \\
\hline Mouse anti-human FoxP3 & Alexa Fluor 488 & 259D/C7 & BD Biosciences \\
\hline
\end{tabular}


Agata Zientarska, Mariusz Kaczmarek, Iwona Mozer-Lisewska, Arleta Kowala-Piaskowska, Aleksandra Witkowska, Jan Żeromski

Table 2. Characteristics of the study group and the control group. In the Mann-Whitney $U$ test, there were no significant differences between female and male subjects in terms of the presented parameters. Data are median (interquartile range)

\begin{tabular}{|c|c|c|c|c|}
\hline Variable & Control & TO & $\mathrm{T} 1$ & $\mathrm{~T} 2$ \\
\hline Total number & 28 & 44 & 44 & 22 \\
\hline Liver cirrhosis & 5 & 29 & 29 & 9 \\
\hline No cirrhosis & 23 & 15 & 15 & 13 \\
\hline Age (years) & $48(30-66)$ & $62(55-69)$ & $62(55-69)$ & $61(51-67)$ \\
\hline Liver cirrhosis & 69 & 62 & 62 & 56 \\
\hline No cirrhosis & 39 & 63 & 63 & 61 \\
\hline Sex (female) & 10 & 21 & 21 & 7 \\
\hline Liver cirrhosis & 2 & 15 & 15 & 3 \\
\hline No cirrhosis & 8 & 6 & 6 & 4 \\
\hline HCV RNA (copies/ml) & 0 & $377,000(39,600-944,000)$ & 0 & 0 \\
\hline Liver cirrhosis & 0 & 260,500 & 0 & 0 \\
\hline No cirrhosis & 0 & 570,000 & 0 & 0 \\
\hline Liver fibrosis (kPa) & $5.4(4.2-7.0)$ & $25.1(8.5-36.3)$ & $15.9(6.5-27.4)$ & $8.6(6.1-18.3)$ \\
\hline Liver cirrhosis & 23 & 34.4 & 25.3 & 27.5 \\
\hline No cirrhosis & 4.4 & 7.7 & 6.4 & 6.8 \\
\hline White blood cells $\left(\times 10^{3} \mathrm{WBC} / \mathrm{mm}^{3}\right)$ & $6.3(5.7-7.2)$ & $5.0(4.25-6.2)$ & $6.1(5.0-7.2)$ & $6.4(5.5-8.2)$ \\
\hline Liver cirrhosis & 5.0 & 4.9 & 5.4 & 5.9 \\
\hline No cirrhosis & 6.8 & 6.1 & 6.6 & 7.6 \\
\hline Lymphocytes (\%) & $23.2(18.7-30.3)$ & $26.5(23.8-33.5)$ & $23.6(18.2-28.2)$ & $24.4(18.5-29.9)$ \\
\hline Liver cirrhosis & 30.0 & 26.0 & 23.7 & 25.6 \\
\hline No cirrhosis & 22.9 & 28.0 & 23.5 & 20.2 \\
\hline Platelet count $\left(\times 10^{3}\right.$ platelets $\left./ \mathrm{mm}^{3}\right)$ & $221(176-261)$ & $107(72-156)$ & $128(90-185)$ & $144(102-203)$ \\
\hline Liver cirrhosis & 120 & 86 & 101 & 102 \\
\hline No cirrhosis & 225 & 175 & 180 & 167 \\
\hline ALT level (IU/ml) & $27(16-37)$ & $58(41-98)$ & $22(17-33)$ & $20(13-23)$ \\
\hline Liver cirrhosis & 18.5 & 65 & 26 & 22 \\
\hline No cirrhosis & 28 & 53 & 17 & 20 \\
\hline AST level (IU/ml) & $23(19-26)$ & $60(37-80)$ & $26(20-35)$ & $21(17-28)$ \\
\hline Liver cirrhosis & 30 & 68 & 31 & 29 \\
\hline No cirrhosis & 20 & 37 & 20 & 17 \\
\hline Total bilirubin $(\mu \mathrm{mol} / \mathrm{l})$ & $9.5(6.8-12.2)$ & $14.8(10.1-22.2)$ & $10.2(7.4-18.7)$ & $9.0(6.8-10.0)$ \\
\hline Liver cirrhosis & 13.5 & 18.4 & 12.1 & 10.0 \\
\hline No cirrhosis & 9.3 & 10.7 & 8.2 & 7.8 \\
\hline Forns index & $3.89(2.25-6.16)$ & $8.63(7.32-9.72)$ & $7.79(5.85-8.72)$ & $6.32(5.09-7.50)$ \\
\hline Liver cirrhosis & 9.04 & 9.06 & 8.28 & 8.03 \\
\hline No cirrhosis & 3.39 & 6.39 & 5.54 & 5.99 \\
\hline Fibrolndex & $0.91(0.52-1.09)$ & $2.11(1.68-2.36)$ & $1.78(1.29-2.07)$ & $1.42(1.01-1.79)$ \\
\hline Liver cirrhosis & 1.72 & 2.24 & 1.89 & 1.83 \\
\hline No cirrhosis & 0.89 & 1.58 & 1.32 & 1.28 \\
\hline FIB-4 & $0.69(0.51-1.47)$ & $4.90(2.65-7.41)$ & $2.99(1.54-3.81)$ & $1.90(1.20-3.11)$ \\
\hline Liver cirrhosis & 3.49 & 6.38 & 3.49 & 3.26 \\
\hline No cirrhosis & 0.62 & 1.84 & 1.58 & 1.34 \\
\hline APRI & $0.26(0.19-0.35)$ & $1.87(0.75-3.21)$ & $0.68(0.42-0.97)$ & $0.39(0.24-0.67)$ \\
\hline Liver cirrhosis & 0.57 & 2.49 & 0.85 & 0.87 \\
\hline No cirrhosis & 0.25 & 0.63 & 0.28 & 0.28 \\
\hline
\end{tabular}

ALT - alanine transaminase, AST - aspartate transaminase 
od, which we described in our previous study [16]. We assessed T regulatory cells' populations present in patients' peripheral blood, using the appropriate monoclonal, fluorochrome-labelled antibodies. The obtained results were analysed with the FACS Diva software (Becton Dickinson), integrated with a cytometer. For each examined antibody, the percentage of positive cells and mean fluorescence intensity (MFI) were determined (Table 1).

The statistical analysis was conducted using STATISTICA software version 13.0 (StatSoft, K, Poland). We applied non-parametric tests as we determined most of our variables not to be normally distributed using the Shapiro-Wilk test. We analysed dependent variables with the Wilcoxon signed-rank test and non-dependent variables with the Mann-Whitney $U$ test. A $p$-value $\leq 0.05$ was considered to be statistically significant [17].

This study was carried out pursuant to the Declaration of Helsinki of the World Medical Association and was approved by the Ethical Committee of Poznan University of Medical Sciences. All the enrolled study participants met the criteria and completed the study. They were fully informed about the study, and all of them expressed written informed consent before their examination.

\section{Results}

\section{General results}

Among the patients qualified for the study, 29 had radiological and biochemical indicators of liver cirrhosis, confirmed by a FibroScan. Leading indicators of the liver function and basic biochemical and morphological parameters are presented in Table 2. After the completed treatment, ALT, AST and total bilirubin level decreased significantly, as well as all the assessed parameters of liver fibrosis $(p<0.05$ for T1 and T2 in all measurements). Platelet count (PLT) and white blood cell count (WBC) increased ( $p<0.05$ for T1 and T2). The percentage of lymphocytes in WBC decreased for T1 $(p<0.05)$, but among patients without liver cirrhosis the lymphocyte percentage remained unchanged despite the treatment.

\section{Changes of Treg lymphocytes}

In the study group before the treatment, median $0.7 \%$ of lymphocytes presented expression of FOXP3+ and were classified as Treg cells. After the treatment, it was $0.35 \%$ for $\mathrm{T} 1$ and $0.30 \%$ for $\mathrm{T} 2$. Volunteers in the control group had a median of $0.4 \%$ Tregs in all lym- phocytes. Although noticeable, differences between those groups were not statistically significant.

When we look at the absolute value of FOXP3 lymphocytes, it was lower in healthy controls than in chronically HCV infected $\left(0.0066 \times 10^{3}\right.$ cells $/ \mu$ and $0.0084 \times 10^{3}$ cells $/ \mu$, respectively, $\left.p=0.048\right)$. After the treatment we observed an insignificant change to $0.0047 \times 10^{3}$ cells $/ \mu$ l for T1 $(p>0.05)$ and a significant fall to $0.0041 \times 10^{3}$ cells $/ \mu$ for T2 $(p=0.03)$ (Fig. 1$)$.

Analysing the group of patients with $\mathrm{CHC}$, we observe no correlation between advancement of hepatic fibrosis and the number of Tregs, regardless of whether we assess the liver condition using a FibroScan, APRI, FIB-4, FibroIndex or the Forns index. We did not statistically prove the slight decrease in the amount of Tregs for patients with cirrhosis observed in Fig. 2.

After a successful DAA treatment, visual analysis of graphs suggests a depletion of circulating Tregs for T2. This dependency was confirmed, as mentioned above, for the whole study group. When we divide patients into subgroups with and without cirrhosis, the change becomes statistically insignificant for both T1 and T2 groups, probably due to the small number of cases and little change. Yet, the visual decrease of Tregs for T2 is similar in both subgroups, as shown in Fig. 3.

Finally, we examined whether Treg cells' change after successful DAA treatment was dependent on hepatic fibrosis degree. As presented in Fig. 4, there was no correlation between the individual difference in the

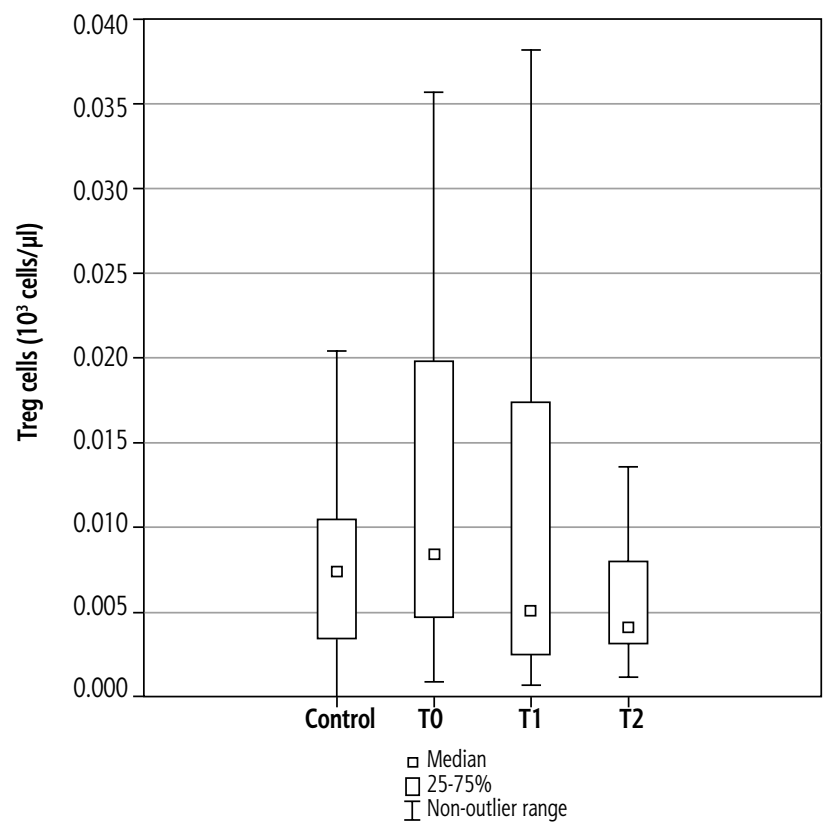

Fig. 1. In the Mann-Whitney $U$ test, there is a significant increase between control and T0 $(p=0.048)$. There is no significant difference between T0 and $\mathrm{T} 1(n=44)$ in the Wilcoxon signed-rank test, while there is a decrease between $\mathrm{T} 0$ and $\mathrm{T} 2(n=22, p=0.03)$ 

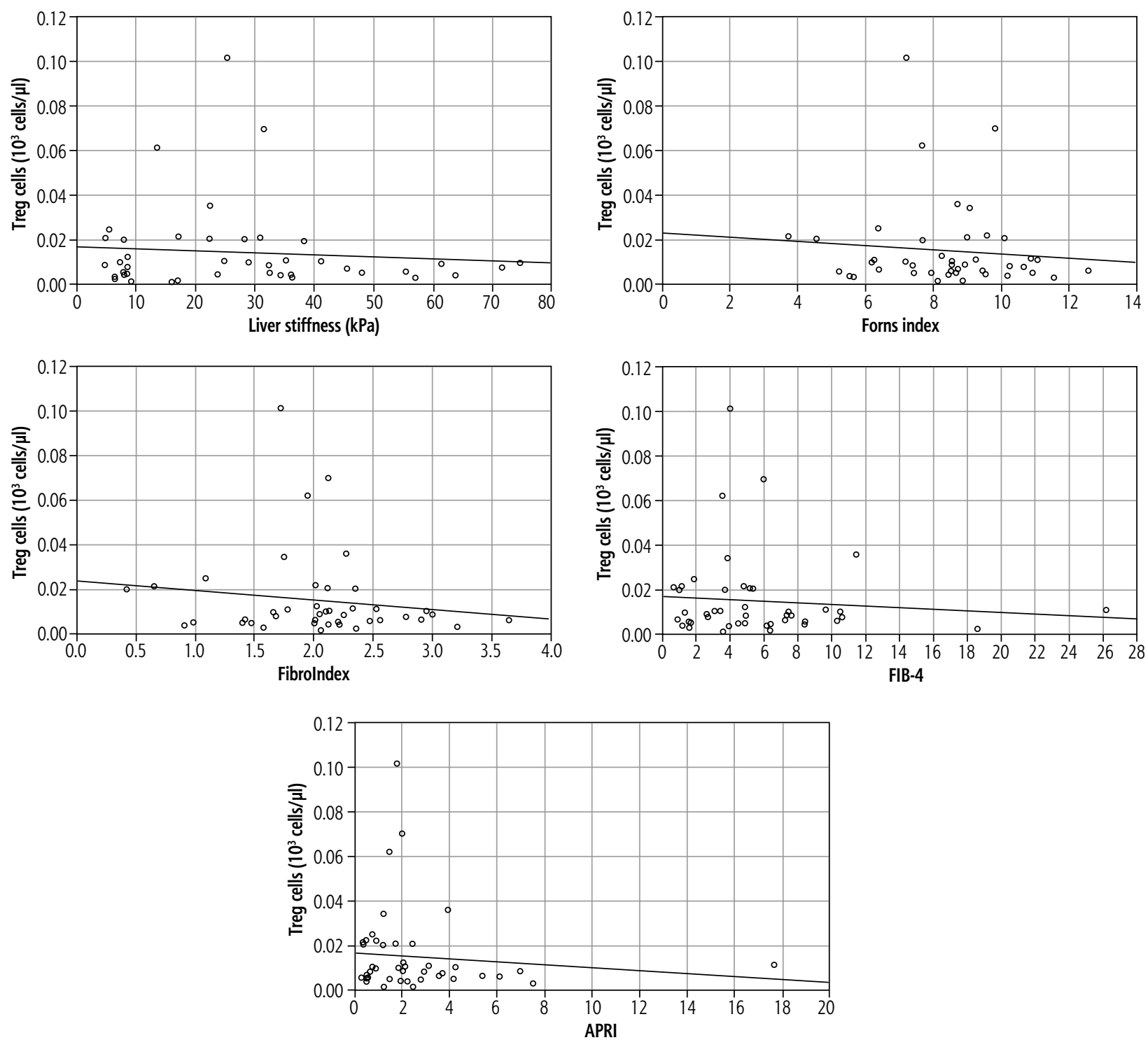

Fig. 2. Correlations between circulating Treg cells and predictors of liver fibrosis before the DAA treatment. In all cases, there is no statistically significant correlation between variables (Spearman's rank correlation coefficient is $>-0.15$, with $p>0.05$ )
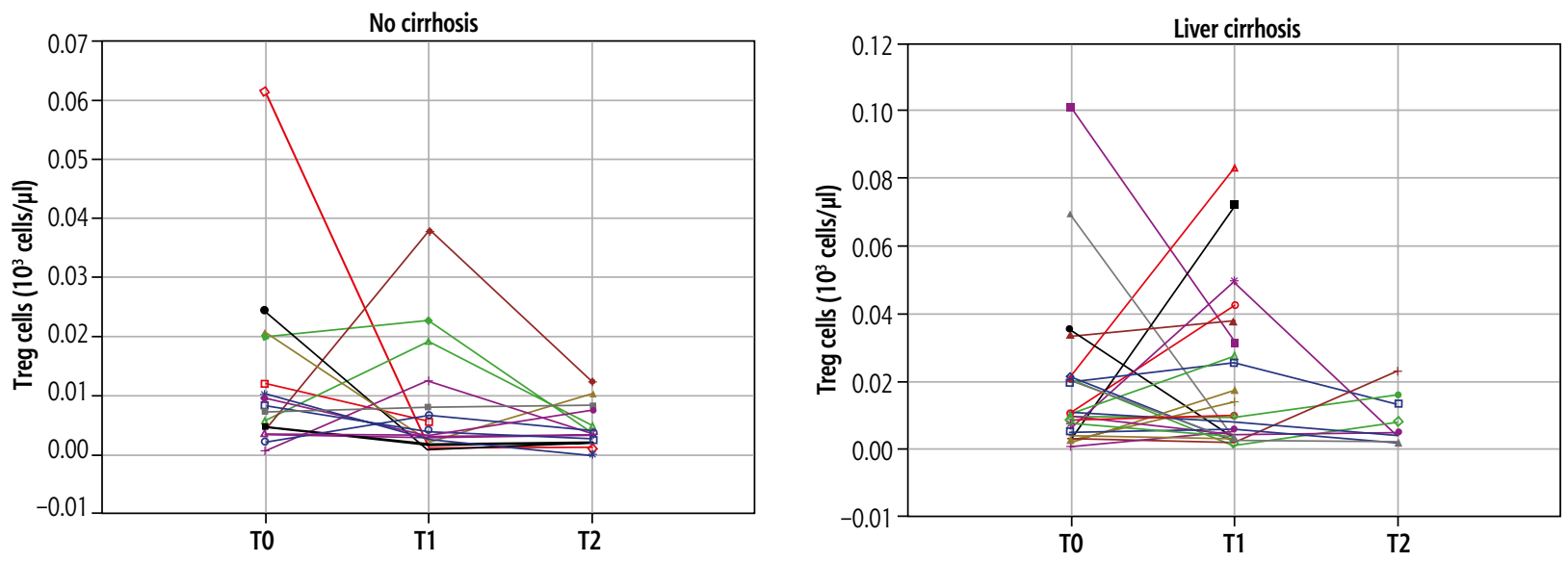

Fig. 3. Change of circulating Treg cells - profiles of cases with and without liver cirrhosis. In the ANOVA Friedman test, statistically significant differences between ranks were not found 
number of post-treatment Tregs and any pre-treatment liver fibrosis indicator. The correlation was not present for either T1 or T2. Then, we juxtaposed the post-treatment change in circulating Treg cells with the post-treatment change in hepatic fibrosis, resulting in no correlation for $\mathrm{T} 1$ or $\mathrm{T} 2$.

\section{Discussion}

In this study, we investigated changes in the amount of circulating Treg cells in patients with $\mathrm{CHC}$ and different stages of liver fibrosis subjected to interferon-free therapy. Our results show that the initially elevated level of Tregs does not decrease after a successful treatment, regardless of the hepatic fibrosis status
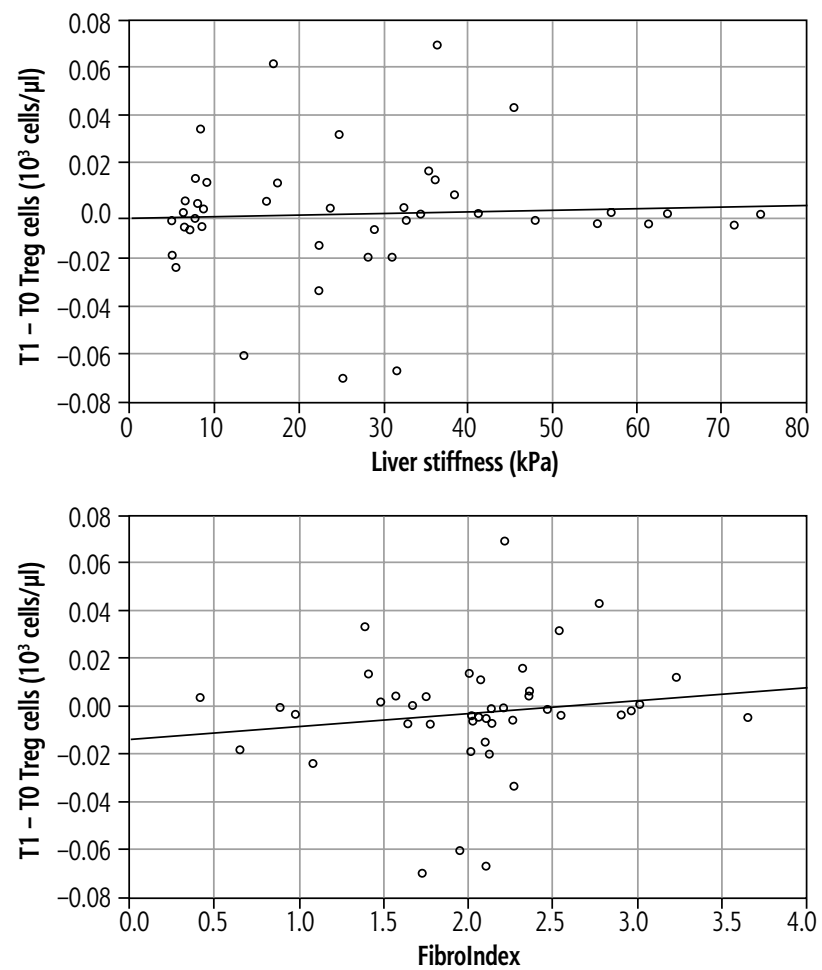

for up to 6 months after the first day of DAA therapy. One year after the beginning of the therapy, circulating Tregs' decrease is becoming noticeable but is still independent of hepatic fibrosis degree. In the study group, the post-treatment levels of Treg cells measured for both $\mathrm{T} 1$ and $\mathrm{T} 2$ did not differ significantly from the controls.

Our findings are partially consistent with similar studies. One recent paper described successful treatment of $14 \mathrm{HCV}$-infected patients at different stages of liver fibrosis using IFN-free regimens. Tregs' frequency and activation status did not normalize for up to one year following the viral elimination [18]. Another study analysed 20 patients with $\mathrm{CHC}$, including only two with liver cirrhosis, during and after DAA treat-
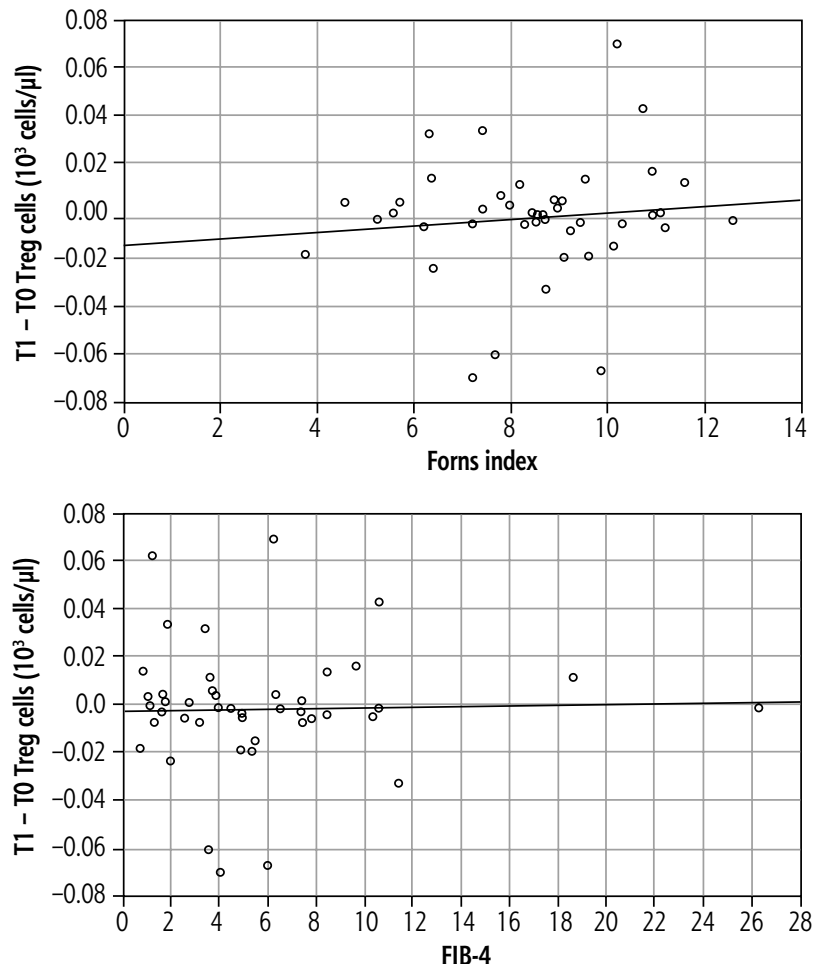

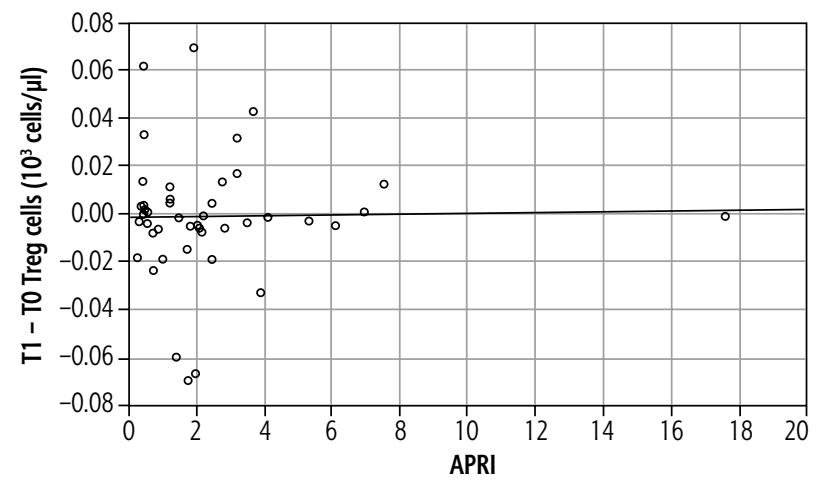

Fig. 4. Treg cells differences before (T0) and after (T1) the DAA treatment. In all cases, there is no statistically significant correlation between variables (Spearman's rank correlation coefficient is $<0.15$, with $p>0.05$ ) 
ment. The frequency and inhibitory function of Tregs declined gradually from baseline to end of treatment (EOT) and then increased from EOT to SVR 12 (sustained viral response 12 weeks after EOT) in CHC patients receiving DAA therapy. Further Treg expansion was not described. The expression of IFN- $\gamma$, tumor necrosis factor $\alpha$ (TNF- $\alpha$ ), interleukin (IL)-10, and TGF- $\beta$ paralleled the Treg function [19]. Comparing those results with our study, we can conclude that Treg cells in CHC patients do not normalize during the first few months after a completed DAA treatment, and may tend to diminish after a longer period. This study is the first to show that this phenomenon is not correlated with the degree of liver fibrosis.

There is strong evidence of Tregs' involvement in intrahepatic immune regulation during $\mathrm{CHC}$ [20]. The level of peripheral Treg cells in patients with liver cirrhosis caused either by HCV or HBV is substantially higher than in healthy controls [21]. Hepatic fibrosis is a wound-healing response to liver injury like a chronic viral infection [22]. Many immune cells and cytokines are involved in this process, and these are regulated, among others factors, by Treg lymphocytes [23]. HCV-specific T CD8+ lymphocytes inhibit viral replication by inducing hepatocyte destruction. In acute HCV, it is observed as a coincidence of intrahepatic CD8+ T-cell responses with a peak in serum ALT, a hepatocyte injury marker [8]. In patients with $\mathrm{CHC}$, circulating CD4/CD8 ratio has a strong, negative correlation with liver stiffness measured by transient elastography [24], which suggests that in CHC, T CD8+ cells also contribute to hepatic injury and progression of fibrosis. Treg cells from patients with CHC show significantly higher suppressive activity against T CD8+ cell proliferation and IFN- $\gamma$ secretion [25], which implies the protective role of Treg lymphocytes in the development of HCV-related fibrosis associated with T CD8+ activity. Nonetheless, in mice with liver cirrhosis of non-viral aetiology, Tregs favour the formation of chronic inflammation and contribute to liver fibrosis's persistence by suppressing NK cells and M1 Kupffer cells more relevantly than inhibiting T CD8+ cells [23]. Thus, Treg cells' role in the development and progression of liver cirrhosis in CHC patients is important but complex and ambiguous.

There is a significant association between Tregs and the occurrence of HCC [26]. In a meta-analysis, the frequency of circulating Tregs in HCC patients was $87 \%$ higher than in healthy controls, and the elevation was also observed in the HCC tumour microenvironment [26]. High levels of Treg cells, both circulating [27] and intratumoural [7], are strongly associated with a poor outcome prognosis, making them potential targets for immunotherapy $[7,28]$. As HCC occurrence or recurrence happens even after successful DAA treatment [29], we can assume that DAA therapy does not eliminate the risk of HCC development connected with Treg activity.

We would also like to highlight the role of Treg cells in different infections that can appear in chronically $\mathrm{HCV}$-infected patients. $\mathrm{CHC}$ is a significant risk factor for opportunistic infections in predisposed patients, such as kidney transplant recipients [30]. Treg lymphocytes restrain activation of effector T-cell responses [31], not being restricted to HCV-specific CD8+ $\mathrm{T}$ cells, but also inhibiting e.g. influenza virus-specific CD8+ T cells [25]. In CHC patients with liver cirrhosis, the increase in circulating Tregs is correlated with and predicts subsequent bacterial complications [32]. Furthermore, there are reports of HBV and varicella-zoster reactivations following the start of DAA therapy $[33,34]$. There is also a description of increased incidence of opportunistic infections in HIV/ HCV coinfected patients appearing around 23 weeks after the beginning of DAA therapy [35]. We cannot exclude that those observations may be related to the persistence of an increased number of circulating Treg cells after DAA therapy.

Our previous study on a small group of obese patients with $\mathrm{CHC}$ showed depletion of the number of Tregs for up to 6 months after treatment to be negatively correlated with pre-treatment body mass [16]. Treg cells' behaviour after a DAA treatment in the context of metabolic disturbances remains elusive and further studies are needed, as metabolic diseases are common in $\mathrm{CHC}$ patients [36].

An important limitation of our study is a lack of assessment of whether the examined Tregs were HCV-specific. However, the persistently increased numbers of those cells doubtless modify the course of liver disease. Tregs not only specifically affect other immune cells, but also modify the liver microenvironment, secreting TGF- $\beta$ and IL-10 or competitively consuming IL-2 [37]. In HCC, tumour-associated Tregs are known to directly promote tumour evasion by several contact-dependent as well as contact-independent mechanisms [28].

\section{Conclusions}

In conclusion, our study showed that Treg cells normalize gradually over a prolonged period of time after successful DAA therapy. Their number and post-treatment dynamics remain independent of liv- 
er fibrosis degree. The relationship of this observation to phenomena such as metabolic disorders, increased susceptibility to infections, or persistent risk of HCC remains unclear.

\section{Acknowledgements}

This work was supported by the National Science Centre, Poland (NCN) grant no. 2016/23/B/ NZ6/01497.

\section{Disclosure}

The authors declare no conflict of interest.

\section{References}

1. Jung MK, Shin EC. Regulatory T cells in hepatitis B and C virus infections. Immune Netw 2016; 16: 330-336.

2. Sugimoto K, Ikeda F, Stadanlick J, et al. Suppression of HCV-specific $\mathrm{T}$ cells without differential hierarchy demonstrated ex vivo in persistent HCV infection. Hepatology 2003; 38: 1437-1448.

3. Barjon C, Dahlqvist G, Calmus Y, et al. Role of regulatory T-cells during hepatitis $\mathrm{C}$ infection: From the acute phase to post-transplantation recurrence. Dig Liver Dis 2015; 47: 913-917.

4. Tseng KC, Ho YC, Hsieh YH, et al. Elevated frequency and function of regulatory $\mathrm{T}$ cells in patients with active chronic hepatitis C. J Gastroenterol 2012; 47: 823-833.

5. Zhai N, Chi X, Li T, et al. Hepatitis $C$ virus core protein triggers expansion and activation of CD4+CD25+regulatory $\mathrm{T}$ cells in chronic hepatitis C patients. Cell Mol Immunol 2015; 12: 743 749 .

6. Claassen MAA, de Knegt RJ, Tilanus HW, et al. Abundant numbers of regulatory $\mathrm{T}$ cells localize to the liver of chronic hepatitis $\mathrm{C}$ infected patients and limit the extent of fibrosis. J Hepatol 2010; 52: 315-321.

7. Yu SZ, Wang Y, Hou J, et al. Tumor-infiltrating immune cells in hepatocellular carcinoma: Tregs is correlated with poor overall survival. PLoS One 2020; 15: 0231003.

8. Shin EC, Sung PS, Park SH. Immune responses and immunopathology in acute and chronic viral hepatitis. Nat Rev Immunol 2016; 16: 509-523.

9. Tseng KC, Ho YC, Tseng CW, et al. Decrease in regulatory T-cell function in chronic hepatitis $\mathrm{C}$ patients receiving pegylated-interferon plus ribavirin. Int J Infect Dis 2017; 58: 8-17.

10. Halota W, Flisiak R, Juszczyk J, et al. Rekomendacje Polskiej Grupy Ekspertów HCV dotyczące leczenia wirusowych zapaleń wątroby typu C w roku 2018 Recommendations by Polish Group of Experts for HCV for the treatment of viral hepatitis C in 2018. Hepatologia 2018; 18: 1-9.

11. Jung KS, Kim SU. Clinical applications of transient elastography. Clin Mol Hepatol 2012; 18: 163-173.

12. Wai CT, Greenson JK, Fontana RJ, et al. A simple noninvasive index can predict both significant fibrosis and cirrhosis in patients with chronic hepatitis C. Hepatology 2003; 38: 518-526.

13. Sterling RK, Lissen E, Clumeck N, et al. Development of a simple noninvasive index to predict significant fibrosis in patients with HIV/HCV coinfection. Hepatology 2006; 43: 1317-1325.
14. Koda M, Matunaga Y, Kawakami M, et al. FibroIndex, a practical index for predicting significant fibrosis in patients with chronic hepatitis C. Hepatology 2007; 45: 297-306.

15. Forns X, Ampurdanès S, Llovet JM, et al. Identification of chronic hepatitis $\mathrm{C}$ patients without hepatic fibrosis by a simple predictive model. Hepatology 2002; 36: 986-992.

16. Kierepa A, Witkowska A, Kaczmarek M, et al. Impact of chronic HCV treatment on quality of life of patients with metabolic disorders in context of immunological disturbances. Sci Rep 2020; 10: 1-10.

17. Skinner J. Statistics for immunologists. Curr Protoc Immunol 2018; 122: 54

18. Langhans B, Nischalke HD, Krämer B, et al. Increased peripheral CD4+ regulatory $\mathrm{T}$ cells persist after successful direct-acting antiviral treatment of chronic hepatitis C. J Hepatol 2017; 66: 888-896.

19. Wu SF, Tseng CW, Ho YC, et al. Regulatory T cell function modulated after successful direct-acting antiviral treatment for chronic hepatitis C patients. Dig Dis Sci 2020; 65: 1385-1395.

20. Ward SM, Fox BC, Brown PJ, et al. Quantification and localization of FOXP3+ T lymphocytes and relation to hepatic inflammation during chronic HCV infection. J Hepatol 2007; 47: 316-324.

21. Niu JQ, Li WY, Jiang YF, et al. Immunologic characterization of posthepatitis cirrhosis caused by HBV and HCV infection. J Biomed Biotechnol 2010; 2010: 138237.

22. Jiao J, Friedman SL, Aloman C. Hepatic fibrosis. Curr Opin Gastroenterol 2009; 25: 223-229.

23. Zhang X, Lou J, Bai L, et al. Immune regulation of intrahepatic regulatory T cells in fibrotic livers of mice. Med Sci Monit 2017; 23: 1009-1016.

24. Feuth T, Van Baarle D, Van Erpecum KJ, et al. CD4/CD8 ratio is a promising candidate for non-invasive measurement of liver fibrosis in chronic HCV-monoinfected patients. Eur J Clin Microbiol Infect Dis 2014; 33: 1113-1117.

25. Boettler T, Spangenberg HC, Neumann-Haefelin C, et al. $\mathrm{T}$ Cells with a CD4+CD25+ regulatory phenotype suppress in vitro proliferation of virus-specific CD8+ T cells during chronic hepatitis C virus infection. J Virol 2005; 79: 7860-7867.

26. Zhao HQ, Li WM, Lu ZQ, et al. Roles of tregs in development of hepatocellular carcinoma: A meta-analysis. World J Gastroenterol 2014; 20: 7971-7978.

27. Zhang AB, Qian YG, Zheng SS. Prognostic significance of regulatory $\mathrm{T}$ lymphocytes in patients with hepatocellular carcinoma. J Zhejiang Univ Sci B 2016; 17: 984-991.

28. Lu C, Rong D, Zhang B, et al. Current perspectives on the immunosuppressive tumor microenvironment in hepatocellular carcinoma: Challenges and opportunities. Mol Cancer 2019; 18: 1-12.

29. Meringer H, Shibolet O, Deutsch L. Hepatocellular carcinoma in the post-hepatitis $C$ virus era: Should we change the paradigm? World J Gastroenterol 2019; 25: 3929-3940.

30. Bodro M, Londoño MC, Esforzado N, et al. Hepatitis C viremia as a risk factor for opportunistic infections in kidney transplant recipients. Clin Transplant 2018; 32: e13382.

31. Kimura A, Kishimoto T. IL-6: regulator of Treg/Th17 balance. Eur J Immunol 2010; 40: 1830-1835.

32. Huang $\mathrm{CH}$, Jeng WJ, Ho YP, et al. Increased regulatory T cells in patients with liver cirrhosis correlated with hyperbilirubinemia and predict bacterial complications. J Gastroenterol Hepatol 2015; 30: 775-783. 
33. Pisaturo M, Macera M, Alessio L, et al. Hepatitis B virus (HBV) reactivation following pharmacological eradication of hepatitis C virus (HCV). Viruses 2019; 11: 850.

34. Ghweil AA, Helal MM. Reactivation of herpesvirus in patients with hepatitis $\mathrm{C}$ treated with direct-acting antiviral agents. Infect Drug Resist 2019; 12: 759-762.

35. Macías J, Téllez F, Rivero-Juárez A, et al. Early emergence of opportunistic infections after starting direct-acting antiviral drugs in HIV/HCV-coinfected patients. J Viral Hepat 2019; 26: 48-54.

36. Younossi Z, Park H, Henry L, et al. Extrahepatic manifestations of hepatitis C: a meta-analysis of prevalence, quality of life, and economic burden. Gastroenterology 2016; 150: 1599-1608.

37. Jeffery HC, Braitch MK, Brown S, et al. Clinical potential of regulatory $\mathrm{T}$ cell therapy in liver diseases: An overview and current perspectives. Front Immunol 2016; 7: 334. 